\title{
Events and the Ontology of Individuals: Verbs as a Source of Individuating Mass and Count Nouns
}

\section{Citation}

Barner, David, Laura Wagner, and Jesse Snedeker. 2008. Events and the ontology of individuals: Verbs as a source of individuating mass and count nouns. Cognition 106(2): 805-832.

\section{Published Version}

http://dx.doi.org/10.1016/j.cognition.2007.05.001

\section{Permanent link}

http://nrs.harvard.edu/urn-3:HUL.InstRepos:3207707

\section{Terms of Use}

This article was downloaded from Harvard University's DASH repository, and is made available under the terms and conditions applicable to Open Access Policy Articles, as set forth at http:// nrs.harvard.edu/urn-3:HUL.InstRepos:dash.current.terms-of-use\#OAP

\section{Share Your Story}

The Harvard community has made this article openly available.

Please share how this access benefits you. Submit a story.

\section{Accessibility}


Events and Individuals 1

To appear in Cognition

Running head: EVENTS AND INDIVIDUALS

Events and the ontology of individuals: Verbs as a source of individuating mass and count nouns

David Barner ${ }^{1}$, Laura Wagner ${ }^{2}$ and Jesse Snedeker ${ }^{3}$

${ }^{1}$ University of Toronto

${ }^{2}$ The Ohio State University

${ }^{3}$ Harvard University 
Abstract

What does mass-count-syntax contribute to the interpretation of noun phrases (NPs), and how much of NP meaning is contributed by lexical items alone? Many have argued that count syntax specifies reference to countable individuals (e.g., cats) while mass syntax specifies reference to unindividuated entities (e.g., water). We evaluated this claim using the quantity judgment method, and tested the interpretation of words used in mass and count syntax that described either protracted, "durative" events (e.g., mass: some dancing; count: a dance), or instantaneous, "punctual" events (e.g., mass: some jumping; count: a jump). For durative words, participants judged, for example, that six brief dances are more dances but less dancing than two long dances, thus showing a significant difference in their interpretation of the count and mass usages. However, for punctual words, participants judged, for example, that six small jumps are both more jumps and more jumping than two long jumps, resulting in no difference due to mass-count syntax. Further, when asked which dimensions are important for comparing quantities of durative and punctual events, participants ranked number as first in importance for durative and punctual words presented in count syntax, but also for punctual words presented in mass syntax. These results indicate that names for punctual events individuate when used in either mass or count syntax, and thus provide evidence against the idea that mass syntax forces an unindividuated construal. They also indicate that event punctuality as encoded by verbs is importantly linked to the individuation of NPs, and may access a common underlying ontology of individuals. 
Events and Individuals 3

Keywords: individuation, syntax, semantics, boundedness, punctual events, mass syntax, count syntax, deverbal nouns 
Events and the ontology of individuals: Verbs as a source of individuating mass and count nouns For the purposes of language, all "things" are equal. Noun phrases can refer to a broad assortment of individual things, including objects, events, ideas, and emotions. These phenomena differ radically in nature, but natural language treats them uniformly in one respect: when used in count syntax, their names denote countable individuals. All words used in count syntax denote individuals (e.g., two books), while most words used in mass syntax do not (e.g., some water). Also, particular words shift meaning when moved from mass syntax - where they quantify by mass or volume, for example - to count syntax - where they quantify by number (e.g., some string vs. some strings). ${ }^{1}$ This effect of syntax on construal led Quine (1960) to posit that count syntax itself is responsible for dividing experience into countable units, and has led others since to propose that only words used in count syntax can denote individuals (Link, 1983; Gordon, 1985; Landman, 1991; Bloom, 1994; Wisniewski, Imai \& Casey, 1996). Such proposals raise the question of whether the linguistic expression of individuals is indeed limited to count syntax, or whether other syntactic structures (e.g., mass or verb syntax) also permit individuation.

Some accounts of this kind assume that individuation requires expression via overt morphosyntax (e.g., via quasi cardinal determiners like these, quantifiers like many, or determiners like a). But if syntax serves as our sole assay for determining whether particular words denote individuals qua individuals, the hypothesis that individuation is limited to count nouns is a mere tautology. However, if individuation is a semantic notion, and not a syntactic one, then it remains possible that words which lack count syntax individuate due to features of particular lexical items (i.e., lexically specified criteria for individuation). Two lines of enquiry suggest that count syntax is not required for individuation. First, several researchers have argued that words used in mass syntax can denote individuals (e.g., furniture; see Gillon, 1999; Chierchia, 1998). This proposal has received empirical support from studies of quantity judgment and word extension. 
Barner and Snedeker (2005) reasoned, following the logic of Quine (1960) and others (e.g., McCawley, 1975; Gathercole, 1985) that if words denote individuals, then they should lead to judgments of quantity based on number (e.g., since "more cats" means "more individual felines"). Barner and Snedeker (2005) found that adults and 4-year-olds judged six tiny shoes to be more shoes than two giant ones, but two large portions of mustard to be more mustard than six tiny portions. In a critical condition, participants also based quantity judgments on number for words used in mass syntax, like furniture, and did so to the same extent that they do for words in count syntax. This result indicates that although count syntax forces individuation, mass syntax also permits reference to individuals when specified by particular words. Similarly, Barner and Snedeker (2006) found that 3-year-old children based the majority of their quantity judgments on number for novel words used in mass syntax that denote solid objects, and that adults based quantity judgments on number about a third of the time when novel names referred to complex physical objects. Based on these data, Barner and Snedeker (2005) proposed the Number Asymmetry hypothesis: whereas count syntax specifies a uniform dimension of measurement - i.e., number - mass syntax is unspecified and permits comparison based on an unbounded range of measuring dimensions, including mass, volume, time, and crucially number (see Barner \& Snedeker, 2005, for discussion, and Gillon, 1999, for a similar proposal).

Studies of word extension have found a similar asymmetry. Numerous experiments have investigated associations between mass-count syntax and the extension of novel words according to the shape or substance of the referents. If count syntax specifies reference to individual objects, then novel words used in count syntax should be extended relatively more by shape than by substance, since shape is diagnostic of object kinds, but not of substances. Similarly, if mass syntax precludes reference to individuals, then words presented in mass syntax should be extended relatively more by substance than by shape. However, although most studies find the 
predicted association between count syntax and shape, they also find that children and adults often associate mass syntax equally with shape and substance information, suggesting that mass syntax does not preclude reference to individuals, but is underspecified. For example, Soja (1992) reported that when children aged 2;6 were taught names for novel objects, they extended these words by shape $90 \%$ of the time when presented in count syntax and $76 \%$ of the time when presented in mass syntax. Using the same method, Barner and Snedeker (2006) found that for complex objects, both 3-year-old children and adults extended novel nouns used in mass syntax by shape more than $50 \%$ of the time (62\% and 53\% respectively). Finally, Subrahmanyam, Landau, and Gelman (1999) found that 3-year-old children accepted the extension of novel words used in count syntax by shape $90 \%$ of the time compared to $86 \%$ for words used in mass syntax. This shape bias for words used in mass syntax decreased with age, to $44 \%$ in older children. Even in adults, subjects continued to accept extension by shape $30 \%$ of the time for words used in mass syntax, which contrasts strongly with the categorical interpretation of count syntax. $^{2}$

The second line of research that questions whether count syntax is necessary for individuation concerns event individuation. Several researchers have argued that names for things share an underlying ontology with event descriptions, such that both permit a grammatical encoding of experience as either 'bounded' or 'unbounded' (Gruber, 1967; Bach, 1986; Jackendoff, 1991; Harley, 2003). As in the object domain, the distinguishing characteristic of a bounded event is that it can be counted (i.e., individuated) while an unbounded event cannot (not, at least, without some sort of explicit packaging of the event). Thus it is felicitous to count instances of falling asleep (1a) but not amounts of sleeping (1b; examples adapted from Bach, 1986).

(1) a. The boy fell asleep three times last night 
b. \#The girl slept for three times last night

Within the event domain, countability requires an event description that specifies units of time. This is transparent in the case of "punctual" events. Punctual events are atomic and take place instantaneously (e.g., in contrast to "durative" events, which take place over extended intervals). Verbs that denote punctual events can be identified and differentiated from verbs that denote durative events using tests of iterativity. Punctual verbs, but not duratives, receive iterated interpretations in the progressive or when paired with a temporal phrase that specifies a more protracted duration. For example, the most natural interpretation of the sentences in 2 (with punctuals) is that the event happened multiple times (i.e., iteratively), while the sentences in 3 (with duratives) describe single protracted events.

(2) a. The baby burped for hours.

b. The baby was burping.

(3) a. The boy danced for days.

b. The boy was dancing.

The application of this test contains a subjective dimension - namely, how long the temporal phase should be relative to the time span of the event - but this is not a fatal problem. While it is possible to obtain non-iterated readings from the sentences in 2 given the right context (e.g., a college student may well be able to continuously burp for long periods of time), the durative predicates never get an iterated interpretation. Even if we expand the temporal phrase to its limits (The boy danced for his whole life) the sentence still doesn't specify an iterated series of discrete dancing events (the most natural interpretation has a generic flavor: the boy was a dancer). Further, many verbs with punctual interpretations resist non-iterated readings (and the unnatural abilities of college students) altogether (4).

(4) a. The boy jumped for hours. 
b. The girl hiccoughed for hours.

There is some evidence that punctual verbs and individuating noun phases have common underlying representations that cause each to individuate. This evidence comes from the study of words that can take on both noun and verb incarnations in the syntax (e.g., to jump, a jump; to hammer, a hammer). By some accounts (e.g., DiSciullo \& Williams, 1987; Selkirk, 1982;

Lieber, 1992), these flexible words begin in the lexicon with either noun or verb features, and are converted via lexical rules to the opposite category. "Deverbal nouns" are nouns derived from words lexically specified as verbs (e.g., jump), and "denominal verbs" are verbs derived from words lexically specified as nouns (e.g., hammer). Upon conversion, the new word assumes all of the syntactic properties of a word from the opposite category (e.g., allowing an item stored lexically as a verb to appear as the head of a noun phrase). Alternatively, it has been suggested that words may begin in the lexicon as neither nouns nor verbs, and instead are assigned their grammatical status upon being projected to the syntax (Barner \& Bale, 2002, 2005; Baker, 2003; Borer, 2005; Halle \& Marantz, 1993, 1994; Marantz, 1997; Harley \& Noyer, 1999). This approach is particularly common in the analysis of the mass-count distinction (see Bunt, 1979; Allen, 1980; Ware, 1979). In both of these traditions, it is normally assumed that the head of a noun phrase (NP) is syntactically a noun, and the head of a verb phrase (VP) is syntactically a verb (see Chomsky, 1970; Kiparsky, 1997; Hale \& Keyser, 1993). Though it is not crucial to our discussion, we will adopt this assumption here for simplicity of exposition, and call derived words simply nouns and verbs (or NPs and VPs where applicable).

Harley (2003) observes that whenever verbs are syntactically derived from words typically used as count nouns, they name bounded individual events. For example, words like "foal" (i.e., baby horse), which denote individuals, can be converted to verbs describing bounded, iterative events (Hale \& Keyser, 1993; see 5). The "for 2 hours" readings in (5) are only acceptable if we 
imagine that multiple births have taken place - i.e., given an iterated interpretation. However, mass NPs like "some drool," which denote unbounded phenomena, result in non-iterative readings, with the opposite pattern of acceptability (see 6; examples from Harley, 2003; Hale \& Keyser, 1993):

(5) a. The mare foaled \#for 2 hours.

b. The dog whelped \#for 2 hours.

c. The cow calved \#for 2 hours.

(6) a. The baby drooled for 2 hours.

b. The athlete sweated for 2 hours.

c. The wound bled for 2 minutes.

Harley notes that a similar phenomenon is found for punctual (7) and durative (8) lexical items, whether used syntactically as nouns or verbs. The example in $7 \mathrm{a}$ is unacceptable unless given an iterated interpretation (where multiple jumps occurred), and $7 \mathrm{~b}$ is unacceptable altogether. However, no similar problem arises for the durative dance, which does not require an iterated reading to occur over a protracted period.

(7) a. Sue jumped \#for 5 minutes.

b. Sue did a jump \#for 5 minutes.

(8) a. Sue danced for 5 minutes.

b. Sue did a dance for 5 minutes.

These examples suggest that certain words maintain the property of individuating or not individuating through their various syntactic incarnations, regardless of whether they denote objects or events. This is consistent with the idea that the ontology of linguistic individuals is not merely a product of particular syntactic constructions like count syntax, but is also a conceptual property encoded by lexical items (see Barner \& Snedeker, 2005). 
Events and Individuals 10

This paper explored two main questions regarding the representation of individual events by NPs and VPs. First, we investigated whether words used as nouns and verbs share a common ontology of individuals. We reasoned that if the individuation of NPs and VPs is due to common features of lexical items, then nouns that are derived from verbs should inherit the verb's individuating features and therefore also individuate. Second, we investigated the claim that only count syntax permits individuation, and that mass syntax forces an unindividuated interpretation. By exploring derived words, we were able to test both questions simultaneously. In English, many words can appear not only in both noun and verb syntax, but also in both mass and count syntax. For example, to describe an event that happened yesterday, I can say that "I jumped", that "I did a jump", or that "I did some jumping". The first example features jump as the head of a VP, the second in a count NP, and the third in a mass NP (despite having verbal morphology, jumping is the head of an NP, and satisfies every available test for diagnosing mass usages). ${ }^{3}$ By all accounts, derived count NPs should individuate because count syntax forces an individuated interpretation. Thus, testing the interpretation of derived count NPs cannot address the question of whether punctuality / durativity affects the interpretation of derived nouns. However, theories differ with respect to their predictions for words used in mass syntax. According to theories in which mass syntax forces an unindividuated interpretation, it is predicted that derived mass NPs will not individuate, whether derived from verbs that denote punctual or durative events. However, if mass syntax does not force a particular interpretation and permits individuation, then punctuality may affect the interpretation of derived NPs and lead to mass NPs that denote sets of individual jumps. Evidence that mass NPs individuate when derived from punctual verbs, but not when derived from durative verbs, would support both the idea that nouns and verbs share an underlying ontology of individuals, and the claim that mass syntax permits individuation. 
Events and Individuals 11

To address these questions, we investigated the interpretation of mass and count NPs derived from both punctual and durative verbs using two tasks. In Experiment 1, we asked participants to identify and rank the dimensions of measurement that they deemed relevant to judging "Who did more" of particular punctual and durative actions. We manipulated whether the names of actions were presented in mass syntax or count syntax. In Experiment 2, we asked participants to make quantity judgments of the form "Who did more $X$ ?" for words punctual or durative words presented in either mass or count syntax. In both experiments, we expected that words used in count syntax would lead participants to favor number as the dimension for measuring events, regardless of whether the word was derived from a punctual or durative verb. Of particular interest was whether participants would also favor number as a measuring dimension for mass NPs derived from punctual verbs, but not for those derived from durative verbs. Evidence that punctual verbs lead to individuating mass NPs would lend support to the hypothesis that mass syntax does not force an unindividuated construal, and the idea that nouns and verbs share a common ontology of individuals.

Iterativity judgments and the punctual vs. durative distinction

As a first step to determining the relation between the lexical semantics of verbs and the quantification of derived NPs, we performed a norming study in which we elicited iterativity judgments from native speakers of English for verbs that can also appear as mass nouns and as count nouns. For example, the word sleep can occur in a light verb construction as either a count noun (e.g., "have a sleep") or as a mass noun (e.g., "do some sleeping"). The goal of this study was to use iterativity judgments to identify prototypical punctual and durative verbs as a precursor to testing how these prototypical cases are interpreted when used in mass and count syntax. We based this assignment on judgments from college students for several reasons. First, we sought to demonstrate that the use of iterativity judgments by linguists reflects not only 
Events and Individuals 12

trained intuitions, but also the intuitions of naïve informants. Second, this method permitted an unbiased selection of items for the subsequent experiments. Finally, and most importantly, the use of these judgments assured that the words used in later experiments were unambiguously punctual or durative for the participants.

\section{Methods}

Participants were 24 English-speaking students recruited from the Harvard University campus. Participants were asked to indicate whether common verbs receive iterative interpretations, as defined below. A total of 44 words were presented to participants. To assure that the verbs were commonly used English words, we drew them from the Macarthur Communicative Development Inventory (MCDI), which documents words comprehended and produced by young children acquiring language (Dale \& Fenson, 1996). Of the 102 action words that appear on the MCDI-2 we determined that 44 could be used in both mass and count noun syntax (see Table 1). These words were presented to participants, each in the phrase " $x$ all day" (e.g., sleep all day), and they were asked to place a check next to each item that they considered to be iterative. The exact instructions for this task were as follows:

"Verbs in English refer to all kinds of actions and events. Among these different action types, a distinction can be made between those that are continuous and those that are "iterative". Continuous actions (e.g., to wander) are defined as actions that can take place over an extended period of time without repetition. Iterative actions (e.g., to stomp) are defined as actions that are not continuous, and must be repeated if they take place over an extended period of time. This intuition can be turned into a test by placing the action word into the sentence: John did " $\mathrm{x}$ " all day. So, you can ask: if you do the action all day (e.g., stomp or wander), does it imply that you must repeat the action over and over, or is 
it possible that one continuous action is performed? Here are the two verbs used in sentences that demonstrate this:

e.g., $\quad$ A. John stomped all day. (means he stomped over and over)

B. John wandered all day (means he wandered continuously)

We call verbs of the " $\mathrm{A}$ " type iterative, because they refer to actions that must be repeated if they are done over a long period of time. We call the " $\mathrm{B}$ " type or continuous because it is not implied that the action must be repeated. Below, we have provided a list of verbs. Using the test provided above, please decide whether each verb is iterative or continuous. Again, the main question is this: is it necessary to repeat the action over and over if it is done all day?"

\section{Results and discussion}

Table 1 summarizes iterativity judgments for each of the 44 target items. Exactly 15 words were judged to be iterative less than $1 / 3$ of the time (i.e., by fewer than 8 subjects). We will call these items "durative". Another 15 words were judged to be iterative more than $1 / 3$ of the time (i.e., by more than 16 subjects). We will call these items "punctual". Presumably the items in the middle category (i.e., that received somewhere between 8 and 16 judgments of iterative) are ambiguous between having iterative and non-iterative interpretations. For example, depending on the context, we can imagine tasting a single flavor over the course of a day (e.g., following a delicious meal), or tasting a particular food over and over. As a result, for later experiments we confined our analyses to items that were given polarized ratings (i.e., the top and bottom 15 words) in order to clearly test the hypothesis that lexical specification of punctuality on verbs influences the quantification of derived nouns. 
Table 1. Number of subjects (out of 24) that judged each action verb to be iterative

\begin{tabular}{|c|c|c|c|c|c|}
\hline \multicolumn{2}{|c|}{ Non-iterative $(<1 / 3)$} & \multicolumn{2}{|c|}{ Ambiguous } & \multicolumn{2}{|c|}{ Iterative $(>2 / 3)$} \\
\hline walk & 0 & wish & 8 & drop & 18 \\
\hline sleep & 0 & drink & 9 & cut & 18 \\
\hline cry & 1 & swing & 9 & fall & 19 \\
\hline run & 1 & sweep & 9 & knock & 19 \\
\hline drive & 1 & pull & 9 & catch & 19 \\
\hline ride & 1 & touch & 10 & lick & 19 \\
\hline talk & 1 & taste & 10 & throw & 20 \\
\hline look & 2 & shake & 10 & bite & 21 \\
\hline dance & 2 & kiss & 13 & bump & 21 \\
\hline swim & 2 & wipe & 14 & jump & 21 \\
\hline smile & 2 & blow & 15 & splash & 21 \\
\hline climb & 2 & stop & 16 & clap & 21 \\
\hline wash & 3 & tickle & 16 & pick & 21 \\
\hline hug & 7 & spill & 16 & hit & 22 \\
\hline push & 7 & & & kick & 23 \\
\hline
\end{tabular}

\section{Experiment 1}

The main question of this study is whether the lexical semantics of verbs are transmitted to derived NPs, and whether the punctuality of certain verbs is related to individuation in mass NPs. Most theories of mass-count semantics state that count NPs uniformly denote individuals, and thus make the prediction that all derived count NPs should lead to quantification based on number, regardless of whether they are derived from punctual or durative verbs. However, theories differ widely in their predictions for mass NPs. If nouns used in mass syntax uniformly denote non-individuals (Link, 1983; Gordon, 1985; Landman, 1991; Bloom, 1994; Wisniewski, Imai \& Casey, 1996), then verb punctuality should have little effect on derived mass NPs. However, if mass syntax is unspecified with regards to individuation (e.g., Barner \& Snedeker, 2005, 2006; Gillon, 1999), then verb punctuality may predict whether particular mass NPs quantify by number (e.g., when derived from punctual verbs), or by some other dimension (e.g., when derived from durative verbs). 
As a first pass at this question, we probed whether mass-count syntax and punctuality (as defined by the iterativity norming study above) affect which dimensions of measurement speakers of English think are relevant to quantifying actions. To do this, we presented participants with punctual and durative words from the norming study, and asked them to rank a set of measuring dimensions according to their relevance to judgments of amount. Words were presented in either mass or count syntax. This method was chosen for two reasons. First, it allowed us to determine the dimensions of measurement that participants spontaneously associate with particular words when provided with a large set of options. Thus, we were able to ask whether punctual words used in mass syntax are spontaneously perceived as more consistent with measurement by number than durative words used in mass syntax. Second, the method allowed us to identify the preferred non-number measuring dimensions for each word, which were used in the creation of the quantity judgment task in Experiment 2 (in which two dimensions were contrasted - number and the highest ranked non-number dimension).

\section{Methods}

Participants were 96 English-speaking students recruited from the Ohio State University campus. Participants were shown one of four question sets. Each set included a page of instructions with an example of how ratings might be performed for two familiar nouns (friend and milk), plus 15 action words to rate. For each word, participants were asked to decide which of 10 dimensions were relevant in deciding who has done more of the relevant action, and then to rank their selections in order of their relevance. Participants were asked to rate either the punctual or durative words from the above norming study, as follows:

“On the following page there are 15 words that name actions. With each is a list of dimensions that people might use to calculate amounts of stuff. For example, we calculate how much milk we have by weight or volume, but how many friends we have 
according to number. For each item, check which ways of measuring could be used, and then rank that subset according to which ways you think are preferable or most common. As a general guide, imagine you are trying to decide if you have more (or in the case of actions, have done more) of the thing in question compared to someone else. Which dimensions would help you resolve a dispute of who has "more"."

The complete instructions are shown in Appendix 1. The punctual words were the 15 words most often rated as iterative in the norming study, and the durative words were the 15 words least often rated as iterative. The list of dimensions (see Appendix 1) was presented anew for each word, which was written either in mass or count form at the top of the dimension list (e.g., for punctual: Who did more ... KICKS, or Who did more ... KICKING; for durative: Who did more DANCES, or Who did more ... DANCING). Thus, event type and mass-count syntax were crossed, between subjects.

\section{Results and Discussion}

Participants exhibited a robust mass-count asymmetry in their dimension ratings. First, participants were more likely to check off number as relevant to measuring "who did more" when the word was either used in count syntax, or was a punctual word used in mass syntax (see Figure 1). The proportion of responses for which number was selected as relevant was calculated for each subject and item. These proportions were submitted to an ANOVA with two betweensubjects factors: syntax (mass vs. count) and event type (punctual vs. durative), and a parallel items ANOVA with one within item factor (syntax) and one between items factor (event type). The items ANOVA allowed us to test whether patterns of data are generalizable across items of this kind, and not just across subjects. There were highly significant main effects of syntax ( F1 $(1,92)=52.45, p<.001 ; F 2(1,28)=179.73, p<.001)$, and event type $(F 1(1,92)=25.76, p<$ 
$.001 ; F 2(1,28)=68.64, p<.001)$, and crucially a highly significant interaction between masscount syntax and event type $(F 1(1,92)=14.60, p<.001 ; F 2(1,28)=58.81, p<.001)$.

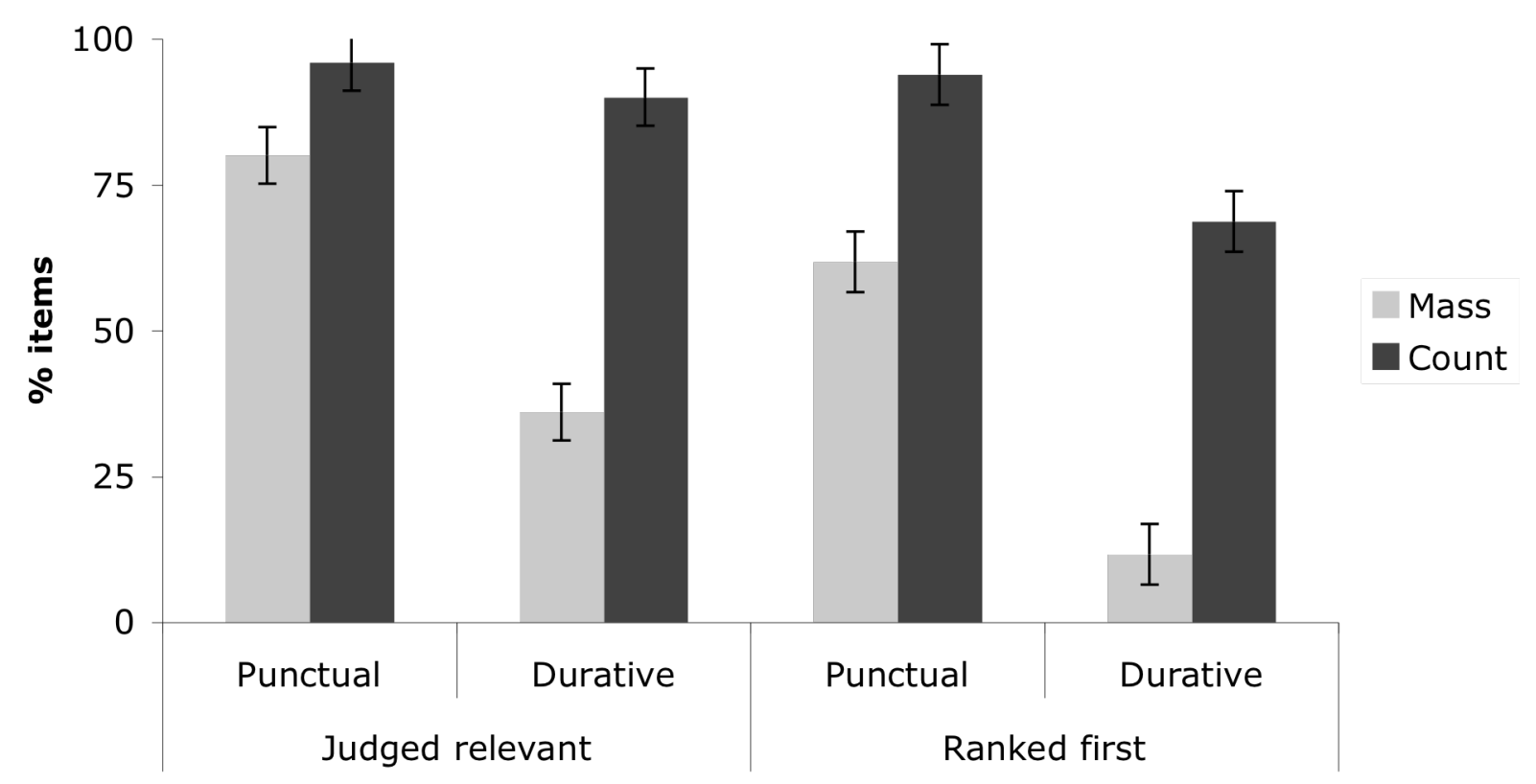

Figure 1. Percentage of items for which number was judged to be relevant, and the percentage for which number was ranked first in relevance, for deciding "who did more" for both punctual and durative words used in mass and count syntax.

Planned comparisons indicated that participants mentioned number as relevant significantly more for punctual items presented in mass syntax ( $80 \%$ of the time) than for durative items presented in mass syntax $(36 \%, t 1(46)=5.2, p<.001 ; t 2(28)=7.97, p<.001)$, but revealed no significant difference between punctual (96\%) and durative (90\%) items in count syntax ( $t 1(46)$ $=1.18, p>.2$; though there was a significant effect in the item analysis $, t 2(28)=4.67, p<$ .001). Also, there was a significant difference in judgments between items presented in mass and count syntax for both for both durative $(t 1(46)=7.07, p<.001 ; t 2(14)=11.18, p<.001)$ and punctual items $(t 1(46)=2.75, p<.01 ; t 2(14)=8.20, p<.001)$.

Second, mass-count syntax and event type also had significant effects on the likelihood that participants would rank number as first in importance for measuring "who did more" of an action (see Figure 1). ANOVAs for subjects and items parallel to the first set were performed, but with 
Events and Individuals 18

the proportion of responses that number was ranked as first in importance as the dependent variable. There was a highly significant main effect of syntax $(F 1(1,92)=73.85, p<.001 ; F 2$ $(1,28)=306.30, p<.001)$, a main effect of event type $(F 1(1,92)=52.58, p<.001 ; F 2(1,28)=$ $105.38, p<.001$ ), and again a significant interaction between mass-count syntax and event type $(F 1(1,92)=5.33, p<.05 ; F 2(1,28)=24.70, p<.001)$. Planned comparisons indicated that participants ranked number as first in importance significantly more for punctual items presented in mass syntax ( $61 \%$ of the time on average) than for durative items presented in mass syntax $(12 \%, t 1(46)=6.93, p<.001 ; t 2(28)=9.22, p<.001)$. Also, there was significant, difference between punctual $(94 \%)$ and durative $(68 \%)$ items in count syntax $(t 1(46)=3.41, p<.01 ; t 2$ $(28)=7.74, p<.001)$. Finally, there was a significant difference between items presented in mass and count syntax for both durative $(t 1(46)=7.81, p<.001 ; t 2(14)=14.08, p<.001)$, and punctual items $(t 1(46)=4.39, p<.01 ; t 2(14)=10.04, p<.001)$.

These results indicate that number is an important dimension of measurement for punctual mass and count NPs, but is less important for durative mass NPs. However, it is also apparent that number is more highly preferred for count NPs than for punctual mass NPs, suggesting that mass syntax leaves judgments open to a broader array of measuring dimensions. To examine this, we performed a final set of ANOVAs (for subjects and items) with the average number of dimensions mentioned per item as the dependent variable, for punctual and durative mass and count items. Overall, participants made reference to 2.29 dimensions on average for items in mass syntax (2.29 for punctual and 2.30 for durative items), and 1.98 dimensions for items used in count syntax (1.7 for punctual and 2.25 for durative items), resulting in a main effect of masscount syntax $(F 1(1,92)=5.55, p<.05 ; F 2(1,28)=24.93, p<.001)$, a main effect of event type $(F 1(1,92)=4.21, p<.05 ; F 2(1,28)=3.85, p<.03$, one-tailed $)$, and an interaction between syntax and event type $(F 1(1,92)=4.08, p<.05 ; F 2(1,28)=17.6, p<.001$; see Figure 
Events and Individuals 19

2). This interaction was driven by participants' selection of fewer dimensions for punctual items used in count syntax, relative to all other conditions. Participants selected more dimensions for durative vs. punctual count nouns $(t 1(46)=2.77, p<.01 ; t 2(28)=3.65, p<.005)$, but showed no difference between punctual and durative words used in mass syntax $(t 1(46)=.02, p>.9 ; t 2$ $(28)=.12, p>.9)$. Also, they showed an effect of mass-count syntax for punctual items $(t 1(46)$ $=3.12, p<.01 ; t 2(14)=7.72, p<.001)$, but not for durative items $(t 1(46)=.24, p>.8 ; t 2(14)$ $=.5, p>.6)$.

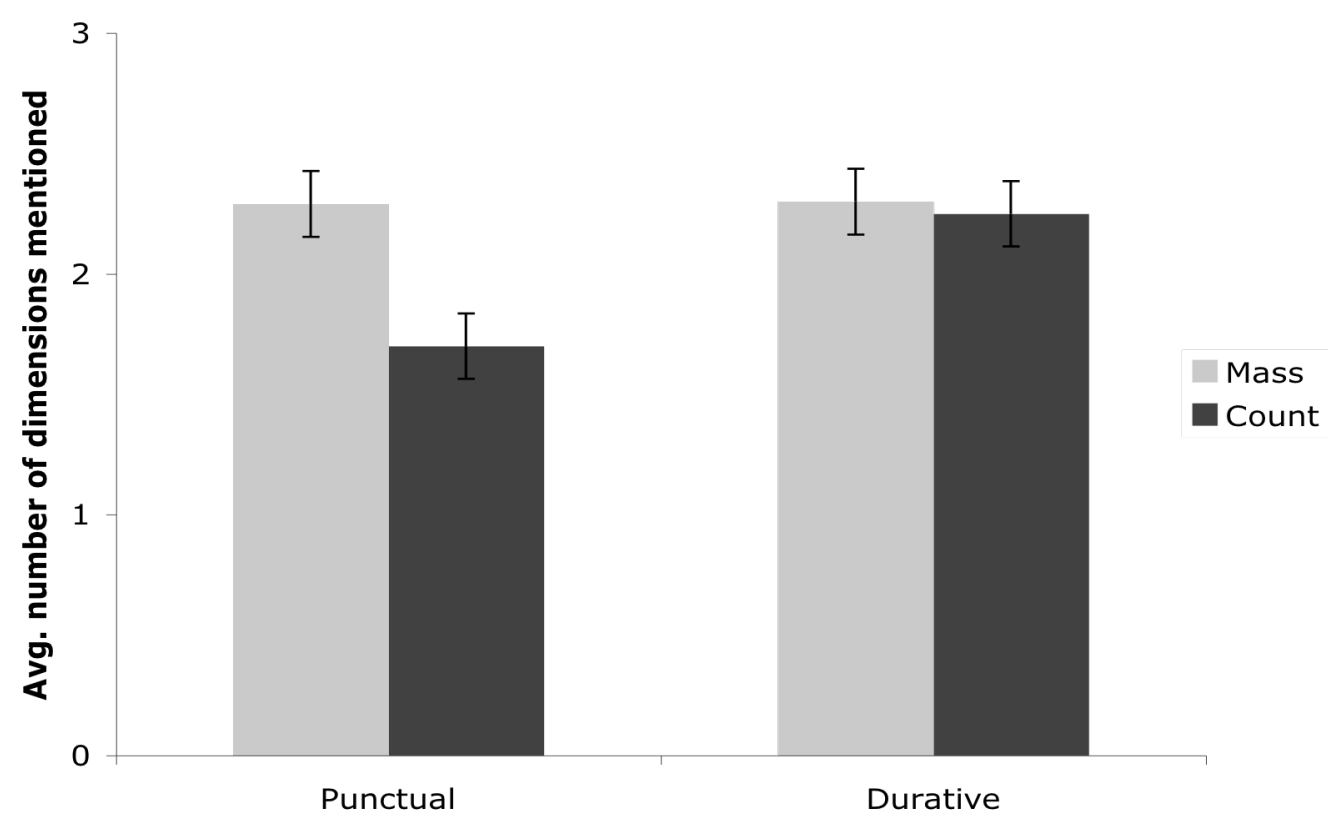

Figure 2. Average number of measuring dimensions listed as relevant for deciding "who did more" for punctual and non-punctual action words used in mass and count syntax.

Thus, participants judged that a broader array of dimensions was relevant to performing judgments of amount when items were presented in mass syntax, compared to when the same items were presented in count syntax, particularly when nouns were derived from punctual verbs. Punctuality appears to restrict the interpretation of derived nouns, particularly when used in count syntax. Presumably, this is because for these NPs, number is specified lexically as the 
default dimension of measurement, whereas for NPs derived from durative words many candidate dimensions of measurement are possible.

To summarize, Experiment 1 indicates that participants take account of punctuality when establishing the measuring dimensions of derived NPs, and that although punctuality affects the perceived relevance of number for all nouns, it does so more for items used in mass syntax relative to items used in count syntax. This result provides preliminary evidence that verb punctuality affects the quantificational properties of derived NPs and does so asymmetrically for mass and count syntax. This hypothesis was tested directly in Experiment 2.

\section{Experiment 2}

The evidence discussed thus far suggests that linguistic tests for diagnosing punctuality are predictive of the perceived relevance of number as a dimension for quantifying action. Further, the evidence suggests that punctuality affects mass and count NPs asymmetrically; there was a significantly larger effect of punctuality on items used in mass syntax relative to items used in count syntax for both rating whether number is relevant to quantification, and for ranking number as first in importance.

The dimension rating task is powerful because it permits participants to select from a large number of possible measuring dimensions and provides detailed information regarding the conceptual representation of particular types of actions. Thus, it assures us that even when a large number of dimensions are offered as possible ways of measuring actions, number predominates for count NPs and for mass NPs derived from punctual verbs. Further, it allows participants to freely conjure mental images or contexts for evaluating each noun, suggesting that significant effects reflect a preferred interpretation of the expressions. However, while the openended nature of the dimension rating makes it a suitable exploratory tool for investigating the lexical semantics of words, it may also lead to variability in responses that cannot be attributed to 
the factors being manipulated (i.e., syntax and punctuality). For example, some participants, when asked which dimensions are relevant to deciding "who did more bites" selected not only number, but also dimensions like depth and diameter - i.e., properties relevant to measuring particular bites, but not to measuring sets of bites. This may have resulted from the fact that participants read each sentence once, but often ranked many dimensions, which may have led them to neglect the syntactic context of items as they checked each subsequent dimension.

To selectively test NP quantification, the second experiment presented participants with quantity judgments for specific scenarios that contrasted two dimensions of measurement. In the vignettes two characters performed an action or sequence of actions (e.g., walking, jumping). One character performed a greater number of actions, while the other performed the action a smaller number of times, but did more of the action along a second dimension (i.e., the nonnumber dimension most frequently rated as relevant to measuring the action in Experiment 1). Given the results of Experiment 1, we predicted that participants would show an asymmetry in their quantity judgments for mass and count syntax, basing judgments on number for all items used in count syntax, and for punctual but not durative items used in mass syntax. Evidence of this kind would support the hypothesis that the lexical semantics of verbs affects the interpretation of derived NPs, and does so relatively more for mass syntax, which fails to specify a uniform dimension of quantification.

\section{Methods}

Participants were 64 English-speaking students recruited from the campuses of Harvard University and the Ohio State University. Participants were assigned to one of four conditions: punctual mass, punctual count, durative mass or durative count. Each condition included short vignettes that described two characters performing actions, followed by a quantity judgment question. These action vignettes were followed by a set of control vignettes that asked 
Events and Individuals 22

participants to perform quantity judgments for count nouns that name objects (dog, plate, house, glass) and mass nouns that name non-solid substances (butter, milk, ketchup, toothpaste). These control items were used to verify that the survey method measures the same phenomenon as actout versions of the quantity judgment method, which use real objects and stuff (or photographs thereof).

Table 2. Non-number dimensions most frequently selected as relevant to measuring durative and punctual actions (mass and count conditions combined)

\begin{tabular}{llll}
\hline \multicolumn{2}{l}{ Durative actions } & \multicolumn{2}{l}{ Punctual actions } \\
\hline WALK & distance & PICK & mass \\
CRY & time & LICK & time \\
LOOK & time & CUT & depth \\
DANCE & time & CATCH & time \\
RUN & distance & CLAP & time / intensity \\
SLEEP & time & SPLASH & volume / intensity \\
WASH & time & DROP & height \\
DRIVE & distance & THROW & distance \\
PUSH & intensity & JUMP & height \\
SWIM & distance & HIT & intensity \\
RIDE & distance / intensity & KNOCK & intensity \\
SMILE & time & BUMP & intensity \\
TALK & time & KICK & intensity \\
CLIMB & height & FALL & height \\
HUG & time & BITE & intensity \\
\hline
\end{tabular}

Items used for creating the vignettes were the 15 punctual and 15 durative verbs used in Experiment 1 (and identified in the norming study). For each action vignette, there were two possible dimensions along which a participant could base his or her quantity judgment: (1) number, and (2) the most frequently selected non-number dimension for that dimension, as determined by Experiment 1. The dimensions that were contrasted with number for each item are shown in Table 2. For example, for the iterative word clap, 42 out of 48 participants selected number as relevant to deciding "who did more" claps or clapping (mass and count collapsed), and 22 out of 48 selected time as relevant. Thus, in the vignettes for clapping, one of the two 
Events and Individuals 23

characters performed more individual claps, which the other performed fewer claps over a longer duration. The complete vignette and judgment task for "clapping" is presented below:

Jerry and Jake both clapped enthusiastically after the concert:

Jerry clapped one time per second for 120 seconds.

Jake clapped four times per second for 90 seconds.

Question: Overall, who did more clapping Jerry Jake

Example vignettes from each condition, including controls, are listed in Appendix 2. As shown in this example, each vignette included a quantity judgment question, which asked the participant to judge which of the two characters had performed more of the relevant action. Mass-count syntax was manipulated only at this point. For example, participants in the punctual mass condition were asked "Overall, who did more clapping?" whereas participants in the punctual count condition were asked "Overall, who did more claps?" This allowed us to test whether syntax led participants to base judgments on number or the other measuring dimension. Thus, the task was identical in structure to the quantity judgment method previously used to test mass-count quantification for solid objects (see Barner \& Snedeker, 2005, 2006). As in Experiment 1, derived count NPs were always "zero-derived", meaning that they had no overt derivational morphology aside from the plural "-s", while derived mass NPs were always gerundival (i.e., they featured an "-ing" ending; see footnote 2 regarding their status as mass NPs). In sum, both event type and mass-count syntax were manipulated between subjects. Within each of the 4 conditions, the 15 target words were divided into 3 lists, such that each participant was tested with 5 target action words and 7 control items (object and substance words). Further, each list was presented in 2 orders. Thus there was a total of 24 lists overall. 
To begin, we analyzed quantity judgments for control items (i.e., count: $d o g$, plate, house, glass; mass: butter, milk, ketchup, toothpaste) in order to validate the use of the survey-based quantity judgment method. As expected, participants based quantity judgments on number 95\% of the time for object-denoting count nouns and $3 \%$ of the time for substance denoting mass nouns. Here, and below, planned comparisons were conducted using Wilcox rank-sum tests for comparisons between subjects and items and Wilcoxon signed tests for comparisons within subjects or items (since low variability in responses suggested that the data were not normally distributed). A planned comparison indicated that the difference between these two types of word was reliable $(W 1(117)=6903, p<.001 ; W 2(4)=16, p<.05)$. Thus, the survey-based quantity judgment method produced categorical judgments for prototypical mass and count nouns, thereby replicating previous versions of the method that used real objects or photographs of objects rather than text descriptions (Barner \& Snedeker, 2005, 2006).

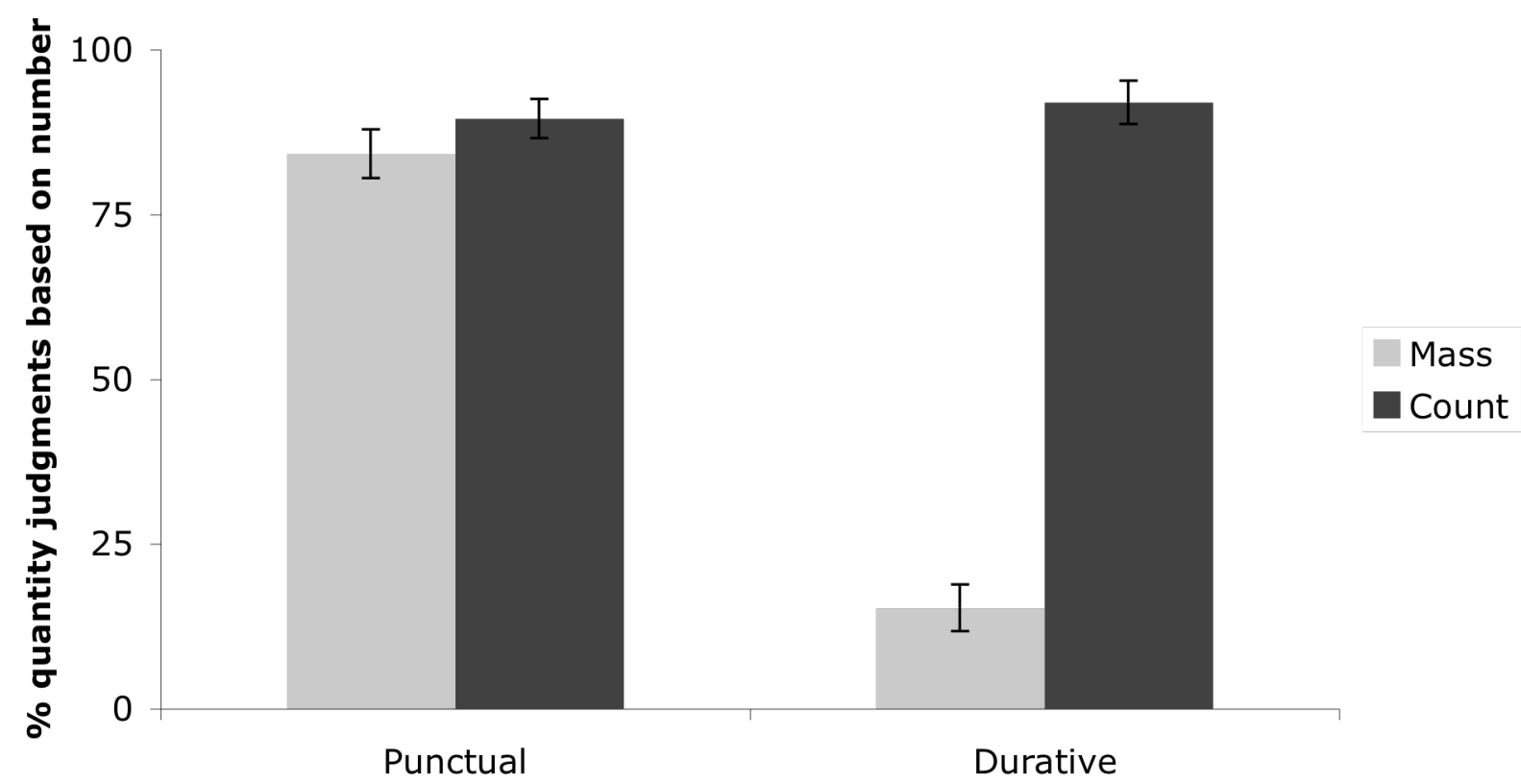

Figure 3. Percentage of quantity judgments based on number for both punctual and durative nouns used in mass and count syntax. 
Events and Individuals 25

Next, we analyzed quantity judgments for derived mass and count NPs. Participants exhibited a clear mass-count asymmetry in their quantity judgments. They based almost all judgments on number for items used in count syntax, regardless of punctuality, but shifted their judgments for items used in mass syntax according to their event type (see Figure 3 ). The proportion of responses based on number was calculated for each subject and item. These proportions were submitted to an ANOVA with two between-subjects factors: syntax (mass vs. count), and event type (punctual vs. durative), and a parallel items ANOVA with one within item factor (syntax) and one between items factor (event type). There were highly significant main effects of syntax $(F 1(1,116)=148.54, p<.001 ; F 2(1,28)=165.08, p<.001)$, and event type $(F 1(1,96)=108.54, p<.001 ; F 2(1,28)=78.65, p<.001)$, and crucially a highly significant interaction between mass-count syntax and event type $(F 1(1,116)=108.54, p<.001 ; F 2(1,28)$ $=120.63, p<.001)$. Participants based judgments significantly more on number for punctual words used in mass syntax ( $86 \%$ of the time on average) than for durative words used in mass syntax $(15 \%, W 1(30)=883.5, p<.001 ; W 2(15)=224, p<.001)$ but revealed no significant difference between punctual (92\%) and durative (92\%) items in count syntax $(W 1(30)=471, p>$ $.7 ; W 2(15)=116, p>.7)$. Also, there was a significant difference between mass and count judgments for durative items $(W 1(30)=887.5, p<.001 ; W 2(15)=120, p<.001)$ but no difference due to syntax for punctual items $(W 1=513, p>.3 ; W 2(15)=28, p>.2)$.

In sum, the results from this study indicate that count syntax imposes individuation, while mass syntax leaves the specification of individuation up to particular lexical items. As suggested by previous studies, mass-count syntax exhibits asymmetry in its interpretation (Barner \& Snedeker, 2005, 2006). Lexical properties that surface when words are used as verbs (e.g., punctuality) also play a role in determining the interpretation of corresponding derived mass 
Events and Individuals 26

usages. If a verb names a punctual event, its corresponding mass NP individuates; if it names a durative event, the corresponding mass NP does not individuate.

\section{General Discussion}

This study of mass-count quantification provides the first experimental evidence for a link between verb event individuation and mass-count quantification. The lexical properties of individual verbs - i.e., their encoding of punctual events - are directly reflected in the interpretation of derived noun phrases. Mass NPs derived from punctual verbs led speakers to base quantity judgments on number more frequently than those derived from durative verbs. This effect of event type on mass NP interpretation was also reflected by the frequency with which number was mentioned as relevant to measurement, and the frequency that number was ranked as first in importance. These results support the idea that punctuality in verbs and individuation by NPs result from related if not identical ontologies of individuals.

Our results also provide strong evidence that mass syntax does not force an unindividuated construal. As noted above, various linguists and psychologists have proposed that only count NPs denote individuals and sets of individuals. Supporters of this view have suggested that apparent counterexamples - e.g., mass NPs like some furniture that name discrete, countable objects in the world - are unproblematic insofar as they fail to pick out individuals in the world qua individuals (see Bloom, 1994; McCawley, 1975; Wisniewski, Imai \& Casey, 1996). Tasks that reveal judgments based on number, for example, might depend on the complexity of physical objects in an array (rather than their linguistic representations) or on the semantics of subordinate noun forms (e.g., chair in place of furniture).

However, the results of this study support a different conclusion. First, it is true that count syntax imposes quantification over individuals, even if corresponding VPs or mass NPs do not. This is demonstrated here by event-denoting count NPs like a dance and a swim. Though the 
Events and Individuals 27

relevant mass usages do not quantify over individuals, the count usages do, as reflected in the quantity judgment task. Second, mass NPs derived from punctual action verbs also denote individuals. This is demonstrated by event-denoting words like jump. These words do not denote complex physical objects, nor are they superordinate terms that might be subject to special semantic considerations. Instead, they are abstract terms that provide linguistic criteria for individuation, just like count nouns. Thus, these data provide strong support for the Number Asymmetry hypothesis: whereas count syntax specifies a uniform measuring dimension (i.e., number), mass syntax leaves the dimension of measurement open to specific lexical items, permitting number as a possible dimension among many others.

\section{Superordinate mass nouns and individuation according to function}

A primary motive for studying action-denoting nouns is that previous empirical studies of the mass-count distinction have focused almost exclusively on nouns that denote objects and substances. The focus on objects and substances in previous studies including our own (e.g., Barner \& Snedeker, 2005, 2006; Soja, 1992; Gathercole, 1985; Gordon, 1985, etc.) has made it difficult to distinguish the contribution of mass-count syntax to meaning from the contribution of particular lexical items, and whether observed differences across the categories are due to syntax or particular ways in which word meanings happen to cluster. Until now, most theories of the mass-count distinction have focused on explaining four categories of words: object-denoting count nouns (e.g., table, cup), substance denoting mass nouns (e.g., water, milk), mass-count flexible nouns (e.g., stone, string), and what we have called object-mass nouns (e.g., furniture, mail). A typical approach has been to seek a common semantics for all mass nouns, to match a common semantics for all count nouns, resulting in either theories in which all mass nouns denote atoms (or individuals; e.g., Chierchia, 1998) or theories in which no mass nouns denote atoms (e.g., Link, 1983). In this context, it is tempting to salvage the second type of theory, in 
Events and Individuals 28

which mass nouns do not denote atoms, by explaining away object-mass nouns. Among nouns that denote concrete, physical stuff, whether objects or substances, almost all mass nouns quantify by mass or volume (e.g., milk, water, sand, rice, wood, etc.). Even when such things have countable parts, as with rice or sand, these parts do not appear to affect quantification. For example, English speakers judge that two long hairs are more hair than six tiny hairs (Inagaki \& Barner, to appear). In light of such apparent systematicity, it seems desirable to integrate somewhat rare cases like furniture and jewelry to this model, and to seek a theory of lexical semantics that explains why these items only seem to denote individuals. Thus, significant space has been devoted to theories of superordinate mass nouns, like furniture, in particular (Barner \& Snedeker, 2005; Chierchia, 1998; Gillon, 1999; Markman, 1989; McCawley, 1975; Prasada, 1999; Quine, 1960; Wisniewski, Imai \& Casey, 1996, etc.).

One important proposal for integrating object-mass nouns to a "non-atomic" theory of mass nouns was first described by McCawley (1975) and has since been adopted by psychologists such as Prasada (1999) and Gordon and Rodman (2006). In his discussion of the mass-count distinction, McCawley suggests that superordinate mass nouns like furniture may not individuate, but instead may quantify over the extent to which a given function is fulfilled. Following the logic of the quantity judgment method, he asks us to imagine a situation where Fred has " 4 chairs, 3 magazine racks, 2 coffee tables, and 1 lamp, and I have 2 chairs, 1 desk, 1 bed, 1 sofa, and 1 table." In this scenario, McCawley concludes that his six pieces of furniture constitute more furniture than Fred's ten pieces do (see Gordon \& Rodman, 2006, for empirical support for this conclusion). What matters is not the number of individuals, but the extent to which the function of furnishing is carried out (Prasada, 1999). According to McCawley, "the meanings of furniture, clothing, and presumably also footwear... are not of the form 'articles for 
Events and Individuals 29

doing $\mathrm{X}$ ' but are rather simply 'for doing X', for example, clothing would be 'for wearing' or 'to be worn'... and furniture would mean something like 'to support persons and objects.' (p. 171)

McCawley's proposal clearly seeks to address both the lexical semantics of nouns like furniture and the contribution of mass syntax to the meaning of these nouns. However, we believe that the proposal encounters difficulty on both counts. Specifically, we question whether the functional definition of superordinate categories denoted by certain mass NPs is evidence that they do not individuate. This proposal encounters several empirical difficulties, some of which McCawley notes in stating the problem of object-mass nouns, but does not resolve. First, he observes that words like furniture select adjectives in a way more similar to object-denoting count nouns than to other mass nouns. For example, it is acceptable to talk about big furniture and big jewelry (or mail, footwear, ammunition, etc.) but much less acceptable to talk about big sand or big water (see also Bunt, 1983). It is impossible, actually, to imagine how adjectives of size could modify anything other than the size of things in this context, and especially difficult to see how they could describe the extent of a function. Related to this, it is impossible to make sense of how we talk about things like furniture in general, without assuming that the word denotes physical phenomena: we talk about painting furniture, bumping into it, or even burning it. Further, this physicality is not optional; object-mass nouns do not exhibit the often-noted polysemy of words like book or newspaper, which can describe either physical things, information, or, in the case of newspaper an organization (see Pustejovksy, 1995). While it is possible to say that the library burned down and was forced to move across the street (since library denotes both a thing and a function, or institution housed by the thing), it is not possible to burn furniture and then move it across the room (although prior to being burned it can be moved). If new objects are purchased to furnish the fire-damaged room, they are new furniture despite the fact that they serve the exact same function. 
Events and Individuals 30

The problem, we suspect, arises from two facts. First, words like furniture and jewelry do in fact categorize things according to their function. Furniture picks out only those things that fulfill a relevant function, and as noted by Prasada (1999), individual pieces, like chairs, contribute incrementally to fulfilling the function of the superordinate: we can talk about a room being partially furnished. However, the relation between furniture and "to furnish", is, in this respect, hardly different from hammer and "to hammer". The noun hammer picks out things according to their function, it does not pick out functions. Further, in the same way that a room can be partially furnished, a nail can be partially hammered, and for that matter, a yard can be partially treed, although tree is a count noun. In general, it does not follow that kind categories defined by functions pick out functions in the world. Instead, they pick out things according to the functions that they fulfill.

Regarding McCawley’s empirical data (reproduced experimentally by Gordon \& Rodman, 2006), we concur that in these particular contexts the noun furniture is demonstrably not quantifying over individual pieces, but over kinds (another type of countable individual). Having 5 kinds of furniture (in 5 pieces) amounts, in some contexts, to having more furniture. Indeed, many mass nouns can quantify over individual kinds when used in count syntax (e.g., who tasted more wines last night), and presumably this is made more salient by the superordinate nature of object-mass nouns. Words like furniture are remarkable, we have noted (Barner \& Snedeker, 2005) in not permitting a count noun use, even to refer to kinds, despite appearing as count nouns in languages such as Spanish and French. We suspect that the failure of object-mass words to permit count syntax is due to the fact that in English, like in these other languages, words like furniture pick out not only individual kinds, but also individual pieces, and in general mass nouns that denote individuals can never be converted to count syntax (Barner \& Snedeker, $2005)^{4}$ 
Events and Individuals 31

To conclude this section, we would like to suggest that progress in the study of syntaxsemantics relations will be made most quickly when the broadest possible set of words - known and novel - are tested. Problems such as those encountered in the analysis of object-mass nouns like furniture provide compelling avenues for research, but should be considered in the broader context of mass and count terms for both concrete and abstract phenomena. When events and other abstract phenomena are considered, it becomes obvious that, unlike count syntax (which specifies comparison by number), mass syntax does not restrict comparisons to a single dimension, like mass or volume, but permits comparison along an unbounded number of dimensions, as indicated by examples like hope, wealth, intelligence, time, dancing and jumping.

\section{The nature of individuals}

Besides providing a powerful test of mass-count semantics, deverbal mass and count NPs offer a window into the nature of linguistic individuals. Few researchers would dispute that count syntax specifies individuation, regardless of how abstract the noun. However, the fact that highly abstract mass NPs can also individuate raises an important question about the nature of the things over which they quantify. In the case of count NPs, it is easy enough to imagine that count syntax might cause shifts in our construal of events, such that even when an action is perceived as a continuous stream of transitions in the world, these transitions are packaged together for linguistic encoding. In this case, we could attribute the source of individuation to the syntax itself, without a pre-specified set of conceptual criteria for individuation: count syntax instructs us to look for criteria, whether in the lexical item or in the particular context. However, for mass NPs, conceptual criteria must play a primary role in individuation if nouns like walking and butter are to be distinguished from nouns like jumping and furniture. Hence the question: what defines an individual event? 
Events and Individuals 32

The question of what defines a kind of thing is not new, and the lessons from studies of object kinds apply equally to kinds of events. Most often, physical properties of things satisfy necessary but not sufficient criteria for the application of kind terms. For example, with the exception of geometric terms like circle and square, common count nouns do not denote shapes, but kinds of things that are identified according to their shape (e.g., Soja, Carey \& Spelke, 1992, for discussion). A cat is not any old cat-shaped object, or even any old object with all of the physical properties of a cat, but rather a kind of thing with a particular causal history (i.e., descent from other cats) which results in the thing having a specific set of characteristic physical properties (see Gelman, 2003). Similarly, a hammer is not any old hammer-shaped object, but instead an object that was created with the intent of being a hammer, with all of the corresponding physical properties, such as rigidity, which support the function of hammering (see Bloom, 1997, for discussion).

Actions are also not individuated exclusively on the basis of spatio-temporal cues (e.g., such as successions of movements interspersed by pauses). As demonstrated by the results of this study, the mass NP some walking never individuates, even when used to refer to many short walks, punctuated by pauses. Instead, what distinguishes words like walking from words like jumping is that only the latter type requires the realization of endpoints for satisfying their application, though both types of action may be performed with easily identifiable ends. In the case of jumping the action is not achieved until at least one full jump has been completed. This contrasts with walking; as soon as one has started walking they have walked - it is not necessary to complete "a walk" in order to say that once has walked (although it is necessary for claiming that one has taken a walk). ${ }^{5}$

The difference between walking and jumping is related to what Cheng (1973) called the “divisity of reference" (see Prasada, 1999, for a related proposal, regarding the "arbitrariness of 
Events and Individuals 33

structure"). Cheng proposed that any part or portion of something that is denoted by a mass noun is denoted by the same mass noun. Thus, butter is divisible, since a part of butter is butter. Cat, in contrast, is not divisible, since a part of a cat is not a cat. This principle correctly describes the semantics of many mass and count nouns, but, as noted by Gillon (1999), it fails in a number of important ways. First, it fails for a subset of nouns that can be used flexibly in either mass or count syntax, such as rope, rock, cord, string, stone, and ash. One ash split in two equals two ashes, in the same way that a rope cut in two equals two ropes. In these cases, the lexical items themselves do not provide criteria for individuation but depend on count syntax for specifying reference to individuals. The second exception to Cheng's proposal comes from mass nouns that quantify over individuals - i.e., words like furniture and jumping. These nouns specify nondivisible parts - things like chairs and jumps - no part of which counts as an instance of furniture or jumping. Half a chair is not furniture, and half a jump does not count as jumping, although half of some butter is butter and half of a walk does count as walking.

Lexical semantics interact with mass-count syntax to specify individuation. Sometimes individuation is specified by purely lexical information, as in the case of mass nouns like furniture, jewelry, jumping, and kicking. Other times it is specified purely by count syntax, as in the case of count nouns like ash, rope, walk and swim. And other times, lexical and syntactic components conspire, and count syntax merely highlights a noun's principle of individuation, sometimes amidst other possible interpretations. Words like cat and table individuate both by virtue of lexical criteria and due to syntactic specification of these criteria, though each can be used in mass syntax under special, and sometimes gruesome circumstances.

\section{Summary}

This study of event individuation and mass-count interpretation supports the hypothesis that nouns inherit semantic properties when derived from verbs. When the words are presented in 
Events and Individuals 34

mass syntax, they quantify over individuals when they denote punctual events, and by other dimensions (e.g., time, distance) when they denote durative events. In contrast, count deverbals quantify over individuals regardless of whether they denote punctual or durative events. We therefore find evidence for the Number Asymmetry hypothesis (Barner \& Snedeker, 2006): whereas count syntax specifies individuation, mass syntax is underspecified and permits quantification over individuals when specified by particular lexical items. 


\section{References}

Allan, K. (1980). Nouns and countability. Language, 56, 541-567.

Bach, E. (1986). The algebra of events. Linguistics and Philosophy, 9, 5-16.

Baker, M. (2003). Lexical Categories: Verbs, Nouns, and Adjectives. Cambridge, England: Cambridge University Press.

Barner, D. \& Bale, A. (2005). No nouns, no verbs? Rejoinder to panagiotidis. Lingua, 115, 11691179.

Barner, D. \& Bale, A. (2002). No nouns, no verbs: Psycholinguistic arguments in favor of lexical underspecification. Lingua, 112, 771-791.

Barner, D. \& Snedeker, J. (2005). Quantity judgments and individuation: Evidence that mass nouns count. Cognition, 97, 41-46.

Barner, D. \& Snedeker, J. (2006). Children's early understanding of mass-count syntax: Individuation, lexical content, and the number asymmetry hypothesis. Language Learning and Development, 2, 163-194.

Bloom, P. (1994). Semantic competence as an explanation for some transitions in language development. In Y. Levy (ed.), Other Children, Other Languages: Theoretical Issues in Language Development. Hillsdale, NJ: Erlbaum.

Bloom, P. (1997). Intentionality and word learning. Trends in Cognitive Sciences, 1(1), 9-12.

Borer, H. (2005). Structuring Sense. Oxford, England: Oxford University Press.

Bunt, H.C. (1979). Ensembles and the formal semantic properties of mass terms. In F.J. Pelletier (ed.), Mass Terms: Some Philosophical Problems. Dordrecht, Holland: D. Reidel Publishing Company, 249-277.

Chierchia, G. (1998). Plurality of mass nouns and the notion of "semantic parameter". Events and Grammar, 70, 53-103. 
Events and Individuals 36

Chomsky, N. (1970). Remarks on nominalization. In R.A. Jacobs and P.S. Rosenbaum (eds.), Readings in English Transformational Grammar. Waltham, MA: Ginn and Company.

Dale, P.S. \& Fenson, L. (1996). Lexical development norms for young children. Behavior Research Methods, Instruments, \& Computers, 28, 125-127.

DiSciullo, A.M. \& Williams, E. (1987). On the Definition of Word. Cambridge, MA: MIT Press.

Gathercole, V. (1985). More and more and more about more. Journal of Experimental Child Psychology, 40, 73-104.

Gelman, S.A. (2003). The Essential Child: Origins of Essentialism in Everyday Thought. New York: Oxford University Press.

Gillon, B. (1999). The lexical semantics of English count and mass nouns. In E. Viegas (ed.), The Breadth and Depth of Semantic Lexicons. Dordrecht, Netherlands: Kluwer, 19-37.

Gordon, P. (1985). Evaluating the semantic categories hypothesis: The case of the mass/count distinction. Cognition, 20, 209-242.

Gordon, P. \& Rodman, A. (2006). Functional quantification of object mass nouns in children and adults. Paper presented at the 30th annual Boston University Conference on Language Development.

Gruber, J. (1967). Functions of the Lexicon in Formal Descriptive Grammar. Santa Monica: Systems Development Corporation. Reprinted as part of Lexical structures in Syntax and Semantics, 1976. North Holland Amsterdam.

Hale, K. \& Keyser, J. (1993). On argument structure and the lexical representation of syntactic relations. In K. Hale and J. Keyser, (eds.), The View from Building 20. Cambridge, MA: MIT Press, 53-110.

Halle, K. \& Marantz, A. (1993). Distributed morphology and the pieces of inflection. In S.J. Keyser and K. Hale (eds.), The View from Building 20. Cambridge, MA: MIT Press, 111- 
176.

Halle, K. \& Marantz, A. (1994). Some key features of distributed morphology. MIT Working Papers in Linguistics 21, 275-288.

Harley, H. \& Noyer, R. (1999). Licensing in the non-lexicalist lexicon: Nominalization, roots and the encyclopedia. MIT Working Papers in Linguistics, 32, 119-137.

Harley, H. (2003). How do verbs get their names? Denominal verbs, manner incorporation and the ontology of verb roots in English. In N. Erteschik-Shir and T. Rapoport (eds.), The Syntax of Aspect. Oxford: Oxford University Press, 42-64.

Inagaki, S. \& Barner, D. (to appear). Countability in absence of count nouns: Evidence from Japanese quantity judgments. In S. Inagaki and M. Hirakawa (eds.), Studies in Language Sciences, 8. Tokyo: Kurosio.

Jackendoff, R. (1991). Parts and boundaries. Cognition, 41, 9-45.

Kiparsky, P. (1997). Remarks on denominal verbs. In A. Alsina, J. Bresnan and P. Sells (eds.), Argument Structure. Stanford: CSLI.

Landman, F. (1991). Structures for Semantics. Dordrecht: Kluwer Academic Publishers.

Lieber, R. (1992). Deconstructing morphology. Chicago, IL: University of Chicago Press.

Link, G. (1983). The logical analysis of plurals and mass terms: A lattice-theoretical approach. In R. Bauerle, C. Schwarze, and A. Stechow (eds.), Meaning, Use, and Interpretation of Language. Berlin: de Gruyter.

Marantz, A. (1997). No escape from syntax: Don't try morphological analysis in the privacy of your own lexicon. University of Pennsylvania Working Papers in Linguistics, 4, 201-225.

Markman, E.M. (1989). Categorization and Naming in Children: Problems of Induction. The Learning, Development, and Conceptual Change Series. Cambridge, MA: MIT Press. McCawley, J. (1975). Lexicography and the count-mass distinction. Proceedings of the First 
Berkeley Linguistic Society Conference, 314-321.

Newtson, D. (1973). Attribution and the unit of perception of ongoing behavior. Journal of Personality and Social Psychology, 28, 28-38.

Newtson, D. \& Engquist, G. (1976). The perceptual organization of ongoing behavior. Journal of Experimental Social Psychology, 12, 436-450.

Ojeda, A.E. (to appear). The paradox of mass plurals. In Francis et al. (eds.), Multifaceted and Interdisciplinary Linguistics. The Legacy of Jim McCawley. Cambridge, MA: MIT Press.

Pustejovsky, J. (1995). The Generative Lexicon. Cambridge, MA: The MIT Press.

Prasada, S. (1999). Names of things and stuff: An Aristotelian perspective. In R. Jackendoff, P. Bloom, and K. Wynn (eds.), Language, Logic, and Concepts: Essays in Memory of John Macnamara. Cambridge, MA: MIT Press, xxvii, 119-146.

Quine, W.V.O. (1960). Word and Object. Cambridge, MA: MIT Press.

Selkirk, E. (1982). The Syntax of Words. Cambridge, MA: MIT Press.

Smith, C. (1991). The Parameter of Aspect. Dordrecht: Kluwer.

Subrahmanyam, K., Landau, B. \& Gelman, R. (1999). Shape, material, and syntax: Interacting forces in children's learning in novel words for objects and substances. Language and Cognitive Processes. 14(3), 249-281.

Talmy, L. (1985). Lexicalization patterns: Semantic structure in lexical forms. In T. Shopen (ed.), Language Typology and Syntactic Description III: Grammatical Categories and the Lexicon. Cambridge: Cambridge University Press.

Wagner, L. (2006) Aspectual bootstrapping in language acquisition: Telicity and transitivity. Language Learning and Development, 2(1), 51-76.

Ware, X. (1997). Some bits and pieces. In F.J. Pelletier (ed.), Mass Terms: Some Philosophical Problems. Dordrecht, Holland: D. Reidel Publishing Company, 15-29. 
Events and Individuals 39

Wisniewski, E.J., Imai, M. \& Casey, L. (1996). On the equivalence of superordinate concepts.

Cognition, 60, 269-298. 


\section{Author Note}

Thank you to Jeremy Hartman for his help designing stimuli for these studies, and to Katherine Chow for her helpful feedback on the manuscript. This research was supported by a fellowship from the National Sciences and Engineering Research Council of Canada to D.B. Address correspondence regarding this paper to: David Barner, Department of Psychology, 4020 Sidney Smith Hall, University of Toronto, 100 St. George St., Toronto, ON M5S 3G3. Email address: david.barner@utoronto.ca. Phone number: 416-978-5429. 


\section{Footnotes}

${ }^{1}$ Count NPs, but not mass NPs, can appear in the singular or plural, with cardinal numbers or quasi-cardinal determiners like these. Mass NPs can occur with terms like much, little, etc.

${ }^{2}$ Although these studies typically find significant effects due to mass-count syntax, such effects do not amount to evidence that mass syntax precludes individuation (i.e., the Number Asymmetry hypothesis does not claim mass syntax forces individuation, only that it permits it).

${ }^{3}$ There are at least three available tests for diagnosing whether a noun is mass or count which can be applied to derived mass nouns like jumping and dancing. First, these words, like prototypical mass nouns (e.g., butter, water) can occur with quantifiers like much and a little: e.g., I did a little dancing yesterday, but I didn't do much jumping. Second, they can occur with measure phrases like "a bit" or "an hour": e.g., I did a bit of dancing / an hour of dancing (compare with "I drank a bit of milk / a liter of milk"). Third, they cannot occur with count morpho-syntax such as numerals, singular-plural morphology, or quasi-cardinal determiners (e.g., I did some jumpings; I did many jumping). By some accounts, the presence of verbal morphology on these nouns suggests processes of how they are derived syntactically (or in the lexicon), but they are widely accepted as genuine mass nouns (see Chomsky, 1970; Marantz, 1997, for discussion).

${ }^{4}$ Further research should also examine partitive expressions. It has been noted that words like furniture are acceptable in the partitive (e.g., piece of furniture) a fact which has been taken to mean that furniture in isolation must not denote pieces. We note two facts here. First, pieces of furniture cannot be any old piece in English (they must be complete chairs, tables, etc.). Second, the translation equivalent to furniture in French, meuble, cannot be used directly with the partitive to refer to tables and chairs, although the French noun refers to exactly the same phenomena as the English noun (i.e., it is a superordinate noun that can be used to refer to tables, 
Events and Individuals 42

chairs, etc.). The only difference between these nouns is syntactic, suggesting that the selection of the partitive is based on syntax, not on semantics (i.e., it is not merely licensed by a noun's lack of criteria for individuation, but by the noun's mass-count status). In support of this, plural mass NPs (e.g., guts, brains, clothes; see McCawley, 1979; Gillon, 1999; Ojeda, 2004), which take plural determiners and morphology but mass quantifiers, cannot be used with the partitive, despite clearly failing to pick out individuals in its absence. Again, the selection of the partitive appears to be syntactic and not semantic.

Also, as we have argued elsewhere (Barner \& McKeown, 2005; Barner \& Snedeker, 2006), it is possible that mass and count NPs (for example, at the superordinate level) differ in meaning not because of effects due to syntax, but because only count NPs can specify singularities. While many linguists have noted that plural count NPs and mass NPs share numerous morpho-syntactic and semantic properties (see especially Gillon, 1999), no one questions the idea that only count NPs can explicitly refer to single individuals. Words that denote things which tend to occur in groups, like furniture (Wisniewski, Imai \& Casey, 1997), may be more likely to be acquired as mass nouns because their referents are less often referred to individually as furniture (e.g., relative to things like animals). Experiments in our lab and in others indicate that children are more likely to believe that a word is a mass noun if the word is used to refer to a group of objects than if it refers to a single thing (Barner \& McKeown, 2006; Gordon, 1985), and have no problem extending these novel mass nouns according to shape, especially when they are complex in nature or appear to have a particular function.

${ }^{5}$ Within the event semantics literature, there are in fact two kinds of predicate that require an end-point to define one complete instance of the event: "punctual" predicates and "telic" predicates (see Bach, 1986; Smith, 1991). Punctual predicates (like the ones used in the experiments presented here) describe events which are conceptually atomic and have no internal 
Events and Individuals 43

structure. Telic predicates, in contrast, describe events that have internal structure and that culminate in a countable endpoint, such as "build a house" and "make a sandwich" (see Wagner, 2006). It is therefore possible to say that "John is building a house" before a house has been completed, although the completion of the event requires a specific endpoint - the completion of a house. Punctual and telic predicates can be contrasted with "durative atelic" predicates (walk, swim) which specify no particular end-point and provide no inherent criteria for individuation. 
Appendix 1.. Instructions for the dimension-rating task of Experiment 1.

On the following page there are 15 words that name actions. With each is a list of dimensions that people might use to calculate amounts of stuff. For example, we calculate how much milk we have by weight or volume, but how many friends we have according to number. For each item, check which ways of measuring could be used, and then rank that subset according to which ways you think are preferable or most common. As a general guide, imagine you are trying to decide if you have more (or in the case of actions, have done more) of the thing in question compared to someone else. Which dimensions would help you resolve a dispute of who has "more". For example:

Who has more... MILK

\begin{tabular}{lll}
\hline Can be used to calculate amount? & Dimension & Rank \\
\hline $\boldsymbol{x}$ & Diameter & \\
$\checkmark$ & Volume & 1 \\
$\boldsymbol{x}$ & Height & \\
$\boldsymbol{x}$ & Number & \\
$\checkmark$ & Mass & 2 \\
$\boldsymbol{x}$ & Time & \\
$\boldsymbol{x}$ & Value & \\
$\boldsymbol{x}$ & Distance & \\
$\boldsymbol{x}$ & Intensity & \\
$\boldsymbol{x}$ & Depth & \\
\hline
\end{tabular}

Here, I know I have more milk than my friend if I have a greater volume or mass of stuff. I also know that when these two are considered, other dimensions like diameter, height, number and depth of the portions is not relevant (e.g., a tall glass of milk may have less than a short stubby glass). Also, volume seems a better, or at least more common, way to decide than mass. Here is another example:

Who has more... FRIENDS

\begin{tabular}{lll}
\hline Can be used to calculate amount? & Dimension & Rank \\
\hline $\boldsymbol{x}$ & Diameter & \\
$\boldsymbol{x}$ & Volume & \\
$\boldsymbol{x}$ & Height & \\
$\boldsymbol{\gamma}$ & Number & \\
$\boldsymbol{x}$ & Mass & \\
$\boldsymbol{x}$ & Time & \\
$\boldsymbol{x}$ & Value & \\
$\boldsymbol{x}$ & Distance & \\
$\boldsymbol{x}$ & Intensity & \\
$\boldsymbol{x}$ & Depth & \\
\hline
\end{tabular}

Here, it is straightforward that to decide which of two people has more friends, we simply count each person's friends. Therefore, number is the best way of calculating who has more. For example, it would be strange to claim that I have more friends than another person because my friends are taller or heavier than theirs. What matters is the number of friends, not their other dimensions. 
Appendix 2. Examples of punctual, durative, object, and substance vignettes from Experiment 2. All punctual and durative items were presented with both mass and count syntax, between subjects.

\section{A. Example of a durative word presented in mass syntax}

Jerry and Jake love to drive. Last week:

Jerry drove four times:

To the store on Monday (1 mile)

To the beach on Saturday (2 miles)

To the barber on Thursday (1 mile)

To the dentist on Friday (3 miles)

Jake drove two times:

To the office on Monday (20 miles)

To the park on Tuesday (40 miles)

Question: Overall, who did more driving? Jerry Jake

\section{B. Example of a durative word presented in count syntax}

Jerry and Jake love to walk. Over the past week:

Jerry walked two distances:

Wednesday (20 miles)

Friday (15 miles)

Jake walked four distances:

Monday (1 mile)

Tuesday (3 miles)

Thursday (2 miles)

Saturday (1 mile)

Question: Overall, who did more walks?

Jerry Jake

\section{Example of a punctual word presented in mass syntax}

Jerry and Jake like to jump high in the air. Yesterday:

Jerry jumped four times:

Before breakfast, he jumped 2 inches off the ground.

At lunch, he jumped 4 inches off the ground.

At work, he jumped 3 inches off the ground.

Before bed, he jumped 2 inches off the ground.

Jake jumped two times:

Before lunch, he jumped 14 inches off the ground.

At work, he jumped 18 inches off the ground.

Question: Overall, who did more jumping?

Jerry Jake 


\section{Example of a punctual word presented in count syntax}

1. Jerry and Jake throw footballs. Yesterday:

Jerry threw four times:

From one side of the road to the other (3 yards)

From the tree to the garden ( 2 yards)

From the front door to the porch (2 yards)

From the garden to the front door ( 4 yards)

Jake threw two times:

From the driveway to the back yard (60 yards)

From the shed to the neighbors' house (40 yards)

Question: Overall, who did more throws? Jerry Jake

\section{E. Examples of substance-denoting mass item and object-denoting count item}

1. Example of substance denoting mass item

Jerry and Jake both have butter on their lunch trays:

Jerry has three 1-ounce pats of butter.

Jake has two 3-ounce pats of butter.

Question: Overall, who has more butter? Jerry Jake

2. Example of object denoting count item

Jerry and Jake both own dogs:

Jerry owns three 20-1b. dachshunds.

Jake owns two 150-lb. St. Bernards.

Question: Overall, who owns more dogs? Jerry Jake 